\title{
Introdução à análise estrutural não linear geométrica de estruturas planas via método dos elementos finitos
}

\author{
Neves, N. S. ${ }^{1 *}$, Pinheiro, V. P. ${ }^{2}$ \\ ${ }^{1}$ COPPE - Programa de Engenharia Civil, Universidade Federal do Rio de Janeiro, RJ, Brasil. \\ ${ }^{2}$ Programa de Pós-graduação em Engenharia Mecânica, Universidade Federal de Espírito Santo. ES, Brasil. \\ *natansian@ufrj.br
}

\begin{abstract}
Resumo
A análise estrutural visa estudar o comportamento de estruturas sob diferentes ações, a fim de obter parâmetros e dados importantes para dimensionamentos e projetos, como deslocamentos, tensões e deformações. Todavia, a análise elástica linear convencional não representa adequadamente comportamento real das estruturas, sendo necessário utilizar a análise estrutural não linear. Desta forma, o presente artigo busca introduzir alguns conceitos e aplicações sobre não linearidade geométrica em estruturas reticuladas planas. Para tanto, utiliza-se os procedimentos numéricos de elementos finitos para solução dos modelos estruturais, sendo implementados as rotinas computacionais em ambiente Matlab. A experimentação numérica é direcionada com dois casos testes, uma viga engastada-livre e um pórtico simples. Em síntese, os resultados mostramse bem ajustados com as soluções de referência para ambos os casos estudados, indicando a boa performance do programa desenvolvido.
\end{abstract}

Palavras-chave: Elementos Finitos, Análise estrutural não linear, Código Computacional.

\section{Introdução}

Com o avanço de técnicas construtivas e das pesquisas cientificas, além do emprego de novos materiais, proporcionaram a construção de estruturas mais esbeltas e com alto desempenho nos últimos séculos. Direcionando paralelamente para análise não linear estrutural, que permite uma maior verossimilhança entre o modelo de engenharia e o comportamento real.

Quando se estuda problemas estruturais não lineares, usualmente, consideram-se duas fontes de não linearidade que ocorrem em estruturas e são significativas na pratica da engenharia, devido representar importantes fenômenos que ocorrem nas estruturas quando sujeitas aos carregamentos. A primeira fonte é a não linearidade física, associado ao comportamento constitutivo do material. A segunda fonte é a não lineari- dade geométrica, tendo as estruturas caracterizadas por grandes deslocamentos e/ou rotações, com equações de equilíbrio definidas no estado deformado da estrutura ou também ocorre uma alteração na relação deformação-deslocamento. Ressalta-se ainda que, uma estrutura pode apresentar um comportamento não linear, mesmo que o material seja elástico linear [1].

\section{Equações Gerais}

A formulação de pórticos planos não lineares é baseada no referencial Lagrangiano atualizado, sendo na configuração $C_{1}$, definindo as componentes planas de tensão provenientes do tensor de Cauchy como ${ }^{t} \tau_{x x}$ e ${ }^{t} \tau_{x y}$, e as deformações incrementais de Green ${ }^{t} \varepsilon_{x x}$ e ${ }^{t} \varepsilon_{x y}$. Com base no princípio dos deslocamentos virtuais, podese escrever a equação de equilíbrio incremental 


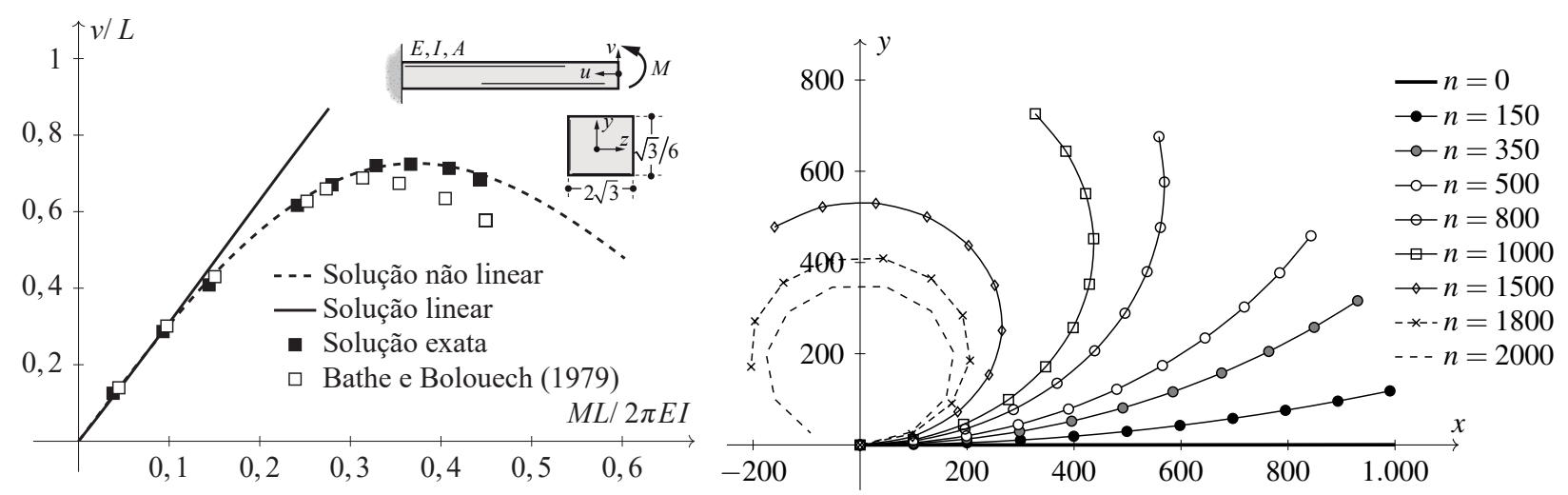

Figura 1: Deslocamento vertical em relação ao fator de carga (esquerda) e deformada da viga engastada-livre com momento na extremidade para diferentes níveis de carga (direita)

do trabalho virtual [2], dado pela Equação (1).

$$
\begin{gathered}
\int_{V}\left({ }^{t} \tau_{x x} \delta \eta_{x x}+2^{t} \tau_{x y} \delta \eta_{x y}\right) d V+ \\
\cdots \int_{V}\left(E e_{x x} \delta e_{x x}\right) d V={ }^{t+\Delta t} R-{ }^{t} R
\end{gathered}
$$

Como a relação deformação-deslocamento é fundamentada pelo tensor de Green-Lagrange, considerando as deformações axiais e cisalhantes, pode-se escrever as relações diferenciais a seguir.

$$
\begin{gathered}
\varepsilon_{x x}=\frac{d u_{x}}{d x}+\frac{1}{2}\left[\left(\frac{d u_{x}}{d x}\right)^{2}+\left(\frac{d u_{y}}{d x}\right)^{2}\right] \\
\varepsilon_{x y}=\frac{1}{2}\left(\frac{d u_{x}}{d y}+\frac{d u_{y}}{d x}\right)+ \\
\frac{1}{2}\left(\frac{d u_{x}}{d y} \frac{d u_{x}}{d x}+\frac{d u_{y}}{d y} \frac{d u_{y}}{d x}\right)
\end{gathered}
$$

Nas Equações (2) e (3), os primeiros termos representam as parcelas lineares e os demais termos correspondem as parcelas não lineares. Adota-se a hipótese de Euler-Bernoulli, que estabelece que as seções transversais planas permanecem normais ao eixo da barra na flexão. Desta maneira, os deslocamentos $u_{x}$ e $u_{y}$, em um ponto genérico, pode ser associados aos deslocamentos $u$ e $v$ da viga. Logo, os deslocamentos são escritos: $u_{x}=u-y v^{\prime}$ e $u_{y}=v$. Após algumas manipulações, chega-se em uma sentença integral definida no domínio contínuo, realizando então as aproximações de elementos finitos, temse:

$$
u=\left\{\tilde{\mathbf{N}}_{1}\right\}\{\bar{u}\} \quad v=\left\{\tilde{\mathbf{N}}_{3}\right\}\{\bar{v}\}
$$

Os termos $\left\{\tilde{\mathbf{N}}_{1}\right\}$ e $\left\{\tilde{\mathbf{N}}_{3}\right\}$ representam os vetores que contêm as funções de interpolação, sendo lineares para deslocamento axial e cúbicas para o deslocamento transversal, respectivamente. As aproximações, apresentadas na Equação (4), são aplicadas na formulação integral do problema. Ao fim, chega-se no sistema algébrico final posto na Equação (5).

$$
\left(\left[\mathbf{K}_{e}\right]+\left[\mathbf{K}_{g}\right]\right)\{\mathbf{u}\}=\left\{{ }^{t+\Delta t} \mathbf{f}\right\}-\left\{{ }^{t} \mathbf{f}\right\}
$$

Onde $\mathbf{K}_{e}$ é conhecido como matriz de rigidez elástica e $\mathbf{K}_{g}$ é a matriz geométrica. Para solução desses problemas, utiliza-se osprocessos incrementais-iterativos, conforme pode ser visto em detalhes em Neves [1].

\section{Experimentação Numérica}

O primeiro caso é uma viga engastada-livre, com momento aplicado na extremidade livre, de comprimento e módulo de elasticidade iguais a 1000, área da seção transversal e o momento de inercia unitários. Para a solução do problema, adotase uma tolerância de $10^{-5}$ e um incremento de carga inicial de $1 \cdot 10^{-2}$. A Figura 1 ilustra o comportamento do deslocamento vertical, medido na extremidade livre da viga, e a deformada da estrutura, onde pode-se notar que a diferença 

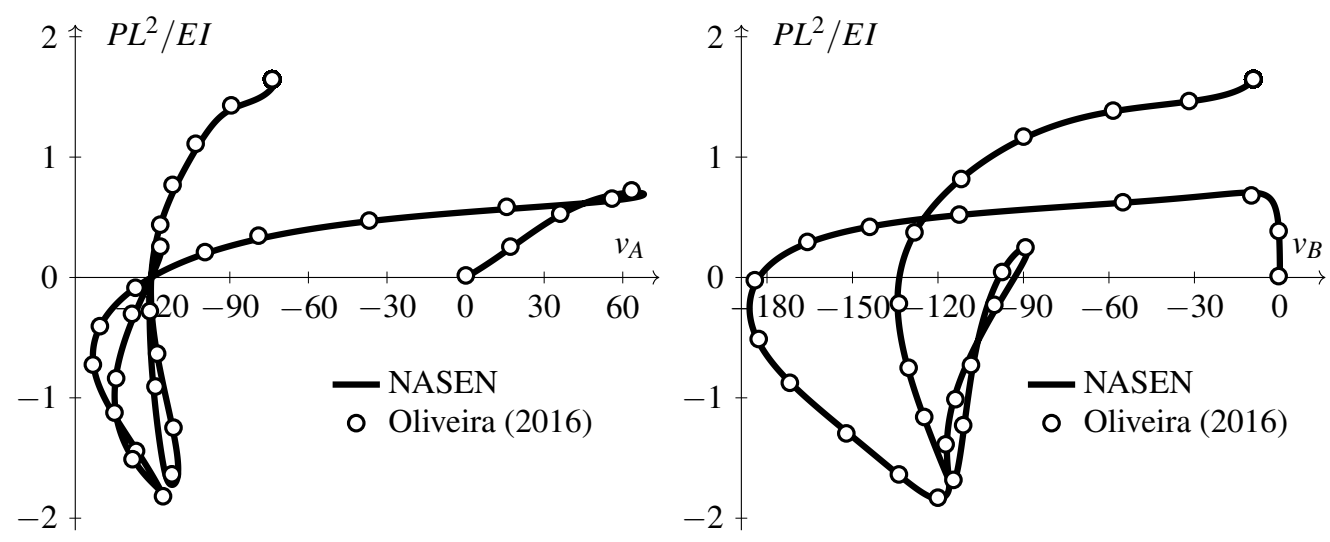

Figura 2: Trajetória de equilíbrio para o deslocamento $v_{A}$ e $v_{B}$

entre as soluções numéricas, considerando ou não os efeitos não lineares.

O segundo caso é composto por um pórtico simples, conforme esquematizado na Figura 3, onde adota-se o módulo de elasticidade igual a $720 \mathrm{kN} / \mathrm{cm}^{2}$. Os parâmetros iniciais do processo incremental-iterativo são iguais ao caso anterior. As medições de resultados são realizadas nas extremidades A e B, visando extrair os deslocamentos verticais em cada ponto.

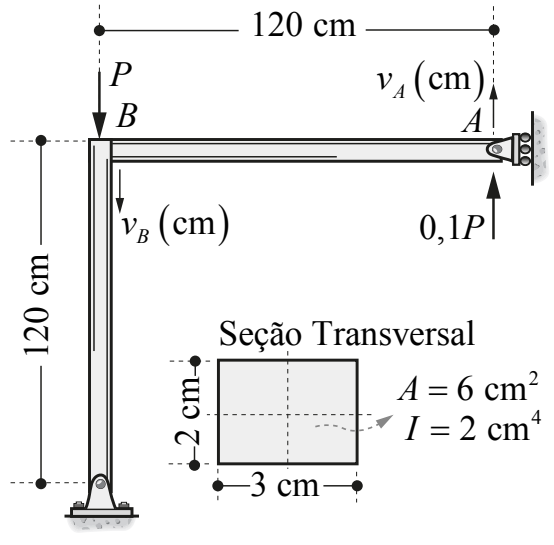

Figura 3: Pórtico de Roorda adaptado

Na Figura 2, mostra-se que os resultados obtidos pelo programa desenvolvido NASEN, apresenta um comportamento semelhante com a solução da literatura. Os caminhos de equilíbrio apresentados indicam inúmeros pontos limites de deslocamento e carga, evidenciando a forte natureza não linear do problema.

\section{Conclusão}

Este artigo buscou apresentam alguns conceitos e as principais sentenças matemáticas de um mo- delo estrutural não linear geométrico via elementos finitos. Após os resultados e testes realizados é possível concluir que o comportamento das estruturas estudados foram bem representadas. Além disso, aprimoramentos e considerações de novas fontes de não linearidade são objetivos para pesquisas futuras, a fim de expandir o módulo de análise estrutural do programa NASEN.

\section{Referências}

[1] NEVES, N. S. Modelo computacional avançado para análise de estruturas sob ação de gradientes térmicos. 2019. 260 f. Dissertação (Mestrado), UFES, Vitória, 2019.

[2] REDDY, Junuthula Narasimha. An Introduction to Nonlinear Finite Element Analysis: with applications to heat transfer, fluid mechanics, and solid mechanics. OUP Oxford, 2014.

[3] BATHE, Klaus-Jurgen; BOLOURCHI, Said. Large displacement analysis of three?dimensional beam structures. International journal for numerical methods in engineering, v. 14, n. 7, p. 961-986, 1979.

[4] OLIVEIRA, G. C. Aplicação do elemento de viga unificado Bernoulli-Timoshenko e da formulação co-rotacional na análise não linear de pórticos e arcos. 2016. Dissertação de Mestrado, UFB, Brasília, Brasil. 